\title{
Jobless Recoveries: The Interaction between Financial and Search Frictions
}

\author{
Dennis Wesselbaum* \\ University of Otago and EABCN
}

Address for correspondence:

Dennis Wesselbaum

Department of Economics

University of Otago

PO Box 56

Dunedin

NEW ZEALAND

Email: dennis.wesselbaum@otago.ac.nz

Telephone: 6434798643 


\title{
Jobless Recoveries: The Interaction between Financial and Search Frictions
}

\author{
Dennis Wesselbaum* \\ University of Otago and EABCN
}

January 12, 2016

\begin{abstract}
This paper establishes a link between labor market frictions and financial market frictions. We present empirical evidence about the relation between search and financial frictions. Then, we build a stylized DSGE model that features this channel. Simulation excercises show that the model with this channel generates a strong internal propagation mechanism, replicates stylized labor market effects of the Great Recession, and, most importantly, creates a jobless recovery.

Keywords: DSGE, Jobless Recovery, Labor Market and Financial Frictions.

JEL codes: C32, E24, E32, J63.
\end{abstract}

${ }^{*}$ University of Otago, Department of Economics. P.O. Box 56, Dunedin 9054, New Zealand. Email: dennis.wesselbaum@otago.ac.nz. 


\section{Introduction}

The recent financial and economic crisis - known as the Great Recession - has shown that disturbances generated in financial markets can create large adverse spill-over effects towards the real economy: A turmoil in the financial and banking system generated a decrease in real and financial wealth which resulted in a drop in aggregate demand and economic activity. One particularly important feature of this recession is the persistently high unemployment rate. Figure 1 plots the evolution of GDP and unemployment during the Great Recession. ${ }^{1}$ We observe that the unemployment rate is still above its pre-crisis level, while output has already exceeded its pre-crisis level. This finding lead many observes to believe in a jobless recovery. Along this line, Calvo et al. (2012) show that financial crises have been associated with jobless recoveries. ${ }^{2}$ They show that financial crises are particularly bad for the labor market as they amplify the usual adverse effects of recessions. Due to the different nature of financial crises it might be expected that they have larger effect on the real economy. However, it is less obvious that they have larger effects on the labor market. Calvo et al. (2012) develop a stylized model with binding collateral constraints and the assumption that labor costs are harder to collateralize than physical capital. Therefore, capital-intensive projects benefit and the recovery becomes "jobless".

Historically, jobless recoveries are a European phenomenon. Blanchard and Summers (1986) argue that high and persistent unemployment rates in Europe are the results of hysteresis due to labor market rigidities. ${ }^{3}$ From the 1990's jobless recoveries can also be found in the United States. Obviously, the rigid labor market hypothesis fails to explains this observation. In contrast, the flexible labor market was blamed to cause jobless recoveries due to structural change, uncertainty, and increasing health costs (see Bernanke (2003) and Groshen and Potter (2003)).

In this paper we establish a link between labor market (search and matching) frictions and financial market frictions. The paper has two goals, (i) empirically establish a link between the two type of frictions and (ii) to present a model with this link in order to discuss the qualitative effects. To be precise, the paper has two contributions and proceeds in two steps: first, we present empirical evidence about the relation between search and financial frictions. Second, we build a stylized DSGE model that features this channel. It should be stressed that the story in this paper is not a propagation story in the sense that combining search and financial frictions will amplify the effect of shocks. ${ }^{4}$ On the contrary, we establish a direct link between the two frictions, a novelty in the literature.

Several results stand out. The first contribution is empirical. We start by constructing the time series for match efficiency and financial frictions. Then, we regress match efficiency on several

\footnotetext{
${ }^{1} \mathrm{~A}$ similar pattern is also found for the Euro Area.

${ }^{2}$ Other papers dealing with the effects of financial crises on unemployment include Reinhart and Reinhart (2010), Bernal-Verdugo et al. (2012), and Chodorow-Reich (2013).

${ }^{3}$ That is to say that the long-run unemployment rate depends on the entire time series of unemployment. For example, due to unions.

${ }^{4}$ For example, Chugh (2009), Petrosky-Nadeau (2014), and Caggese and Perez (2015) study this and related questions.
} 


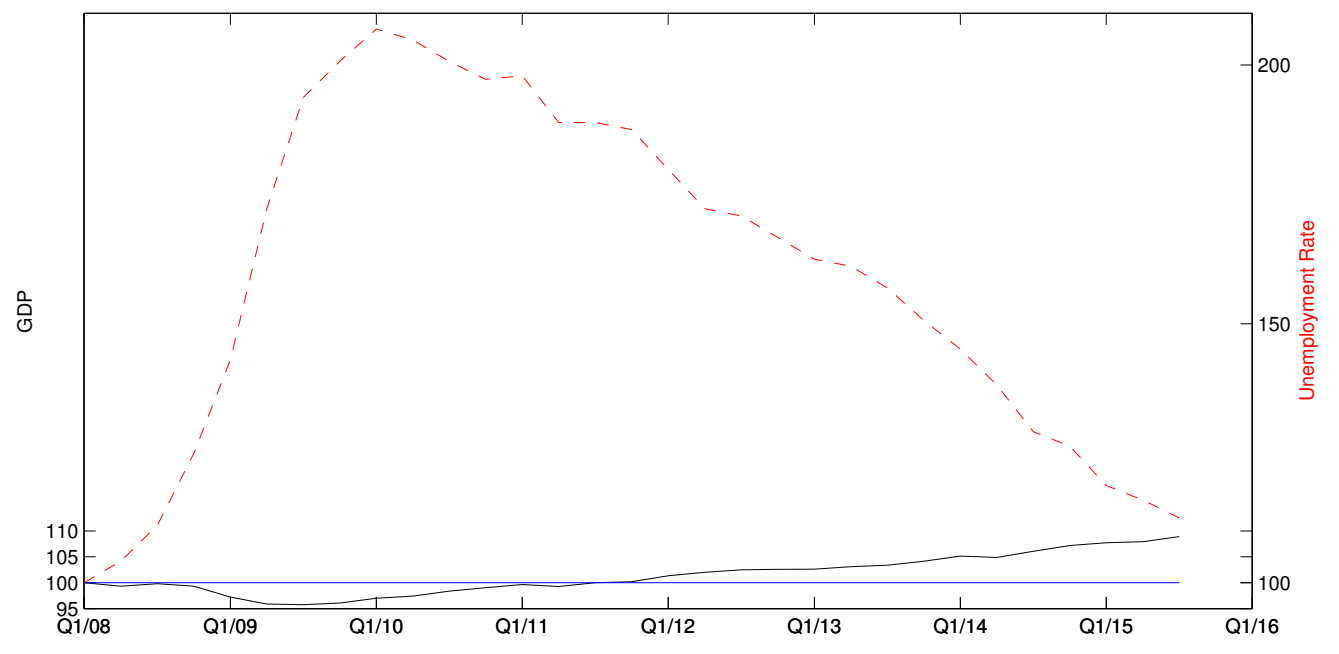

Figure 1: We plot the time series for GDP (left axis) and the unemployment rate (right axis) from 2007Q4 (= 100) until 2015Q2.

explanatory variables including financial frictions. We find that financial frictions are significant as well as several labor market variables. Further, using a rolling window approach, we document time variability in the link between search and financial frictions. While the relation is fairly stable prior to the crisis, during the Great Recession we observe a larger and varying relation between the two frictions. While prior to the crisis we observe a positive relation, in the crisis we observe a negative relation for an extended period of time. A positive relation implies that more frictions in the financial market increase the efficiency of the labor market. Therefore, a negative relation is the worst-case scenario as both frictions increase. As it turns out, this new channel helps to understand jobless recoveries: the negative relation between the two frictions roughly occurs at the same time GDP goes back to pre-crisis levels. Then, we estimate a VECM model, show that a shock to financial frictions increases match efficiency, and discuss major driving forces in a variance decomposition analysis.

The second contribution is theoretical. We build a DSGE model with search and matching frictions and financial frictions that includes our new channel and compare it to a standard model with this channel. We simulate the model and show that the model with a strong, negative relation between the two frictions generates a jobless recovery and creates a strong internal propagation mechanism. Further, the simulated model dynamics are in line with the stylized empirical facts of the Great Recession. The model generates a simultaneous increase in financial frictions and a decrease in match efficiency observed in the empirical part. 


\section{Data}

\subsection{Match Efficiency}

In this section I will discuss how to obtain a time series for match efficiency. For this purpose, I use the search and matching theory developed by Mortensen and Pissarides (1994). ${ }^{5}$ Trade in the labor market is uncoordinated, costly, and time-consuming. Search takes place on a discrete and closed market. Workers can be either employed or unemployed, such that there is no out of labor force option.

If the job is filled, it is subject to the probability of being destroyed $\rho_{t}$. In addition, firms create jobs at the rate $M\left(U_{t}, V_{t}\right)$ at the non-state-contingent cost of $c>0$ units of output per vacancy, where $M$ is the homogeneous-of-degree-one-matching-function,

$$
M\left(U_{t}, V_{t}\right)=m_{t} U_{t}^{\mu} V_{t}^{1-\mu}
$$

where $m_{t}>0$ gives the match efficiency and $1>\mu>0$ is the elasticity of the matching function with respect to unemployment. ${ }^{6}$ Unemployment is given by $U_{t}$ and $V_{t}$ is the vacancy rate.

Further, it can be shown that new matches are equal to

$$
M\left(U_{t}, V_{t}\right)=\left(1-U_{t}\right) \rho_{t} .
$$

Then, combining 1 and 2 gives, as an intermediate step,

$$
U_{t}=\frac{\rho_{t}}{\rho_{t}+m_{t}\left(\frac{V_{t}}{U_{t}}\right)^{1-\mu}},
$$

which, solved for $m_{t}$, gives the equation for the match efficiency at $t$

$$
m_{t}=\left[\frac{\rho_{t}}{U_{t}}-\rho_{t}\right]\left[\frac{U_{t}}{V_{t}}\right]^{1-\mu} .
$$

\section{$2.2 \quad$ Financial Frictions}

Having discussed the measure of labor market frictions, this section discusses a measure of financial frictions following the paper by Hall (2013). In this paper financial frictions, $F F_{t}$, are measured as a spread between the return earned in business from operating physical capital and the return earned by savers.

Technically,

$$
F F_{t}=\underbrace{\frac{1}{Q_{t}}\left[\alpha \frac{Y_{t}}{K_{t}}+(1-\delta) Q_{t+1}\right]}_{\text {Extra units of output }} \underbrace{-\left(1+R_{t}\right)}_{\text {Safe rate }}
$$

where Tobin's Q is defined as

$$
Q_{t}=\kappa\left(\frac{K_{t}}{K_{t-1}}-1\right)+1
$$

\footnotetext{
${ }^{5}$ See Barlevy (2011) and Veracierto (2011) for a similar approach.

${ }^{6}$ Petrongolo and Pissarides (2001) find that the Cobb-Douglas function with constant returns to scale is the most appropriate specification.
} 
and gives the shadow price of physical capital. Here, $\kappa>0$ measures capital adjustment costs. Output is denoted by $Y_{t}$ and the capital stock is $K_{t}$, depreciated at the constant rate $\delta>0$. Assuming a Cobb-Douglas production function, $\alpha$ gives the elasticity of the production function with respect to capital. The safe rate is driven by the real return on capital, $r_{t}$.

From this definition for the spread, (5), it should be clear that the tax wedge, the risk premium, and various spreads from different financial frictions (e.g. agency frictions within producing firms, financial intermediaries, and frictions between financial institutions and investors) are included. This measure of financial frictions is superior to measures that rely on spreads between corporate bonds and U.S. treasury bonds, as they are able to explain the prolonged slump after the financial crisis as shown by Hall (2013).

\subsection{Data Set}

For our empirical analysis we need to obtain time series for match efficiency (4) and financial frictions (5). Therefore, we need several other time series. We use data for the United States starting in 2001:M2 and ending in 2014:M3 (158 observations) being on a monthly frequency.

For the match efficiency we need the unemployment rate taken from the Bureau of Labor Statistics (BLS, for short): LNS14000000, measured in percent for all workers 16 years and over, seasonally adjusted. Second, we use the time series for total separations (as a rate) from the JOLTS database at the BLS: JTS00000000TSR, for total nonfarm separations. Finally, we use the time series for total nonfarm job openings for vacancies (JTS00000000JOR).

For the time series for financial frictions we use the following data. The LIBOR rate (USD12MD156N) from the St. Louis database FRED and the real gross domestic product (GPDMC1) for output. The capital stock series is taken from the Penn World Table 8.0 (RKNANPUSA666NRUG) at constant national prices. If time series are not available at a monthly frequency they are converted into monthly frequency using the quadratic-match average.

\subsection{A Preliminary Look at the Data}

Figure 2 plots the time series for the match efficiency and the financial friction. Doing so requires to calibrate some structural parameters. We assume $\mu=0.18$. The capital share in the production function is set to 40 percent, $\alpha=0.4$. The capital depreciation rate is set to an annual value of 10 percent, $\delta=0.025$. The capital adjustment costs are taken from the estimations by Smets and Wouters (2007) and is set to a value of $\kappa=6$.

We find an almost perfect comovement between financial and labor market frictions until 2009 . An upswing starting at the first recession in our sample (2001) lead to a quite persistent increase in financial frictions but increased efficiency in the labor market. A downturn can be observed starting around 2004 when the labor market became less efficient but the financial market becomes less frictional. The minimum in financial frictions, over our sample period, is obtained during 2006/2007, which is roughly the time the housing bubble in the United States peaked and bursted. From this low financial frictions increased, except for a short but large drop in 2008, until the 


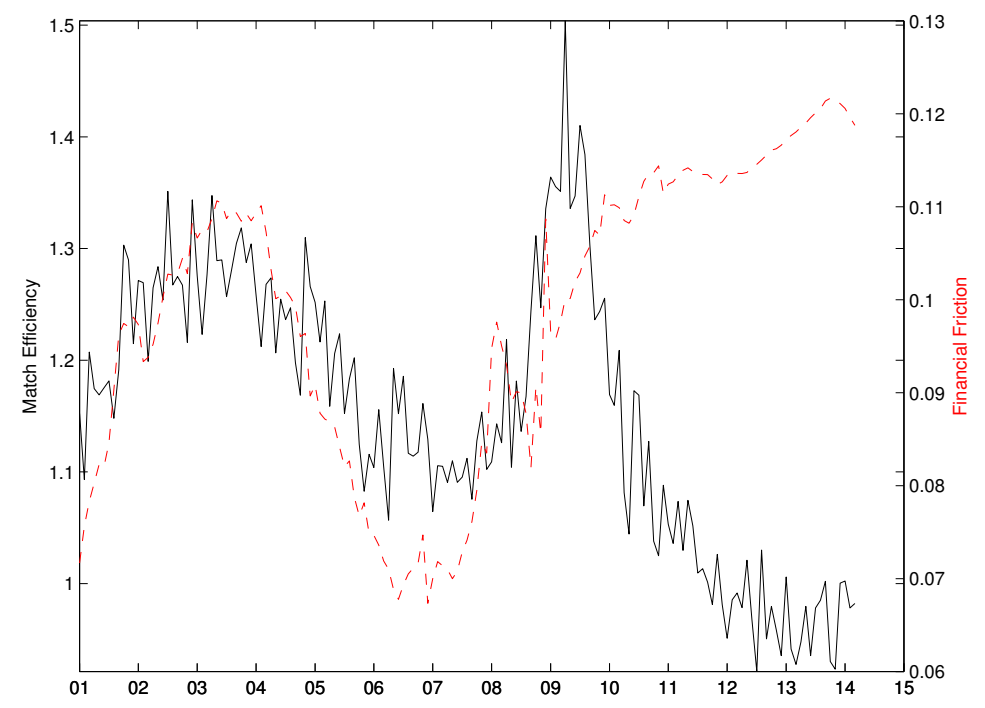

Figure 2: Time Series for the match efficiency (left scale, black solid line) and financial frictions (right scale, red dashed line).

end of our sample. For the labor market, we also observe an increase in match efficiency until 2009, when a sharp negative trend starts that continues until, approx., 2012. For the rest of our sample match efficiency stays roughly constant. What we can infer from the graphical inspection is that prior to the financial crisis and the subsequent Great Recession, high inefficiency in the financial market went hand-in-hand with a high efficiency in the labor market. This holds for the recession in 2001 but does not hold for the Great Recession. It appears that there is something structurally different between the two recessions, although both - for different reasons - started in the financial (i.e. stock) market. This pattern is also visible using a scatter plot of the two time series (Figure 3). It appears that there is a significant positive relation between financial and labor market frictions. This holds roughly until financial frictions are larger than 0.11 . Then, we observe a clear and even stronger negative relationship between the two variables. Again, this is driven by the Great Recession as we have seen values of 0.11 for financial frictions associated with a high match efficiency. Everything above seems to generate a different behavior between the two markets.

The observed pattern might offers some insights into the slow recovery of the U.S. economy. First, higher financial frictions interfere with a proper functioning of the financial markets and, since investment should be inversely related to this friction, this will - ceteris paribus - lead to a lower level of output. Second, a persistently lower match efficiency leads to less jobs created and the value of the out-of-labor force option increases; two phenomenons that we observed in the United States: a strong and fairly persistent increase in the unemployment rate and a drop in the labor market participation rate. 


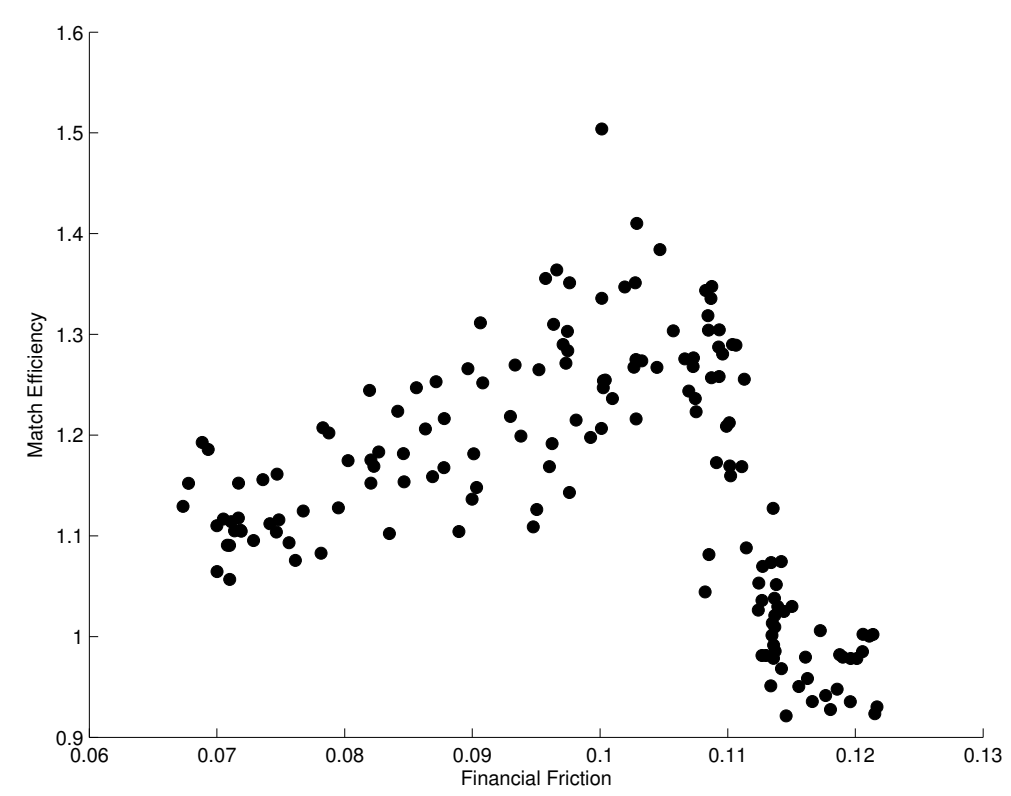

Figure 3: Scatter plot of financial frictions vs. match efficiency.

\section{Estimation}

\subsection{OLS}

Having discussed the time series for match efficiency and financial frictions (spread), we are interested in establishing a link between the two frictions. For this purpose, we start by estimating a single-equation model using OLS. Table 1 presents the estimated coefficients with standard errors and significance levels. Given the size of our data set we estimate the model with two lags and a constant. ${ }^{7}$ Most importantly, the one-period lag of financial frictions (spread) is significant and has the largest coefficient across all variables. Further, our results show that there is a significant contemporaneous and two-month lag for vacancies, separations, and unemployment. While the contemporaneous effect is negative, the lag has a positive effect for unemployment and vacancies. Rather surprisingly, the participation rate and GDP have no significant effect. It should be stressed that higher lags of the participation rate and GDP are significant.

\subsection{Rolling Windows}

In the previous section we have shown that there is a significant effect from financial frictions towards match efficiency. In the following, we want to show that this relation is subject to timeinstability. We use a rolling window OLS regression with a twelve month window size. ${ }^{8}$

\footnotetext{
${ }^{7}$ The estimation with four lags also shows a significant effect of financial frictions on match efficiency. The results are available upon request.

${ }^{8}$ Robustness checks with a six month and an 18 months window supporting our findings are shown in the appendix.
} 
Table 1: OLS estimation results. Significance levels: $1 \%:{ }^{* * *}, 5 \%:{ }^{* *}, 10 \%:{ }^{*} \cdot R_{a d j}^{2}=0.97$.

\begin{tabular}{|c|c|c|c|}
\hline Parameter & Coefficient & Parameter & Coefficient \\
\hline Constant & $\begin{array}{c}-0.0007 \\
0.006\end{array}$ & Separations & $\begin{array}{c}0.35^{* * *} \\
0.01 \\
\end{array}$ \\
\hline Spread & $\begin{array}{c}0.24 \\
0.24 \\
\end{array}$ & Separations $(-1)$ & $\begin{array}{c}0.002 \\
0.008\end{array}$ \\
\hline Spread $(-1)$ & $\begin{array}{c}-0.76^{* * *} \\
0.28 \\
\end{array}$ & Separations $(-2)$ & $\begin{array}{c}-0.01^{* *} \\
0.007 \\
\end{array}$ \\
\hline Spread $(-2)$ & $\begin{array}{c}-0.23 \\
0.19\end{array}$ & Vacancies & $\begin{array}{c}-0.18^{* * *} \\
0.01\end{array}$ \\
\hline Participation & $\begin{array}{l}0.01 \\
0.008 \\
\end{array}$ & Vacancies $(-1)$ & $\begin{array}{c}-0.006 \\
0.007 \\
\end{array}$ \\
\hline Participation $(-1)$ & $\begin{array}{c}-0.002 \\
0.008 \\
\end{array}$ & Vacancies $(-2)$ & $\begin{array}{c}0.19^{* * *} \\
0.01\end{array}$ \\
\hline Participation $(-2)$ & $\begin{array}{c}0.003 \\
0.005 \\
\end{array}$ & $G D P$ & $\begin{array}{c}0.52 \\
0.51 \\
\end{array}$ \\
\hline Unemployment & $\begin{array}{c}-0.04^{* * *} \\
0.006\end{array}$ & $G D P(-1)$ & $\begin{array}{c}-0.84 \\
0.69 \\
\end{array}$ \\
\hline Unemployment $(-1)$ & $\begin{array}{c}0.002 \\
0.005\end{array}$ & $G D P(-2)$ & $\begin{array}{c}-0.08 \\
0.48\end{array}$ \\
\hline Unemployment $(-2)$ & $\begin{array}{c}0.02^{* *} \\
0.008\end{array}$ & & \\
\hline
\end{tabular}

Figure 4 shows the estimated coefficient (in blue) for financial frictions with the 90 percent confidence bands plotted in red. Given that in a rolling windows regression we have less observations, we choose to estimate a parsimonious model. We regress the match efficiency on a constant, lagged match efficiency, financial frictions, and GDP. Therefore, we need to be careful in our assessment of the significance of the estimated parameters. Overall, given that the estimated value of the link between financial frictions and match efficiency is around -0.8 the low number of observations leads to fairly large confidence bands.

Nevertheless, at the beginning of our sample, we find a negative relation between search and financial frictions. One should remind that a negative relation is the worst-case as an increase in financial frictions lowers match efficiency, i.e. increases labor market frictions. This negative relation occurs during the recession of the early 2000's. The unemployment rate started to increase from the beginning of 2001 and peaked in the second quarter of 2002. The negative relation between the two frictions could explain this first jobless recovery in our sample. As financial frictions increased over this period (cf. figure 2), the negative relation implies a drop in match efficiency. As a consequence the labor market is less efficient and it takes, ceteris paribus, a longer period of time to reduce unemployment. After this recession we observe a significant positive relation between the two frictions with small standard errors in 2003 and from 2009 to 2010.

This holds until the emergence of the Great Recession. From the second half of 2011 to the second half of 2013, we find a strong negative relation with values of around -50 . This is the time period during which the unemployment rate should have decreased faster as GDP returned to precrisis levels. The negative spill-over implies a less efficient labor market that clearly interfered with a faster reduction of unemployment. From the second half of 2013 towards the end of our sample, 


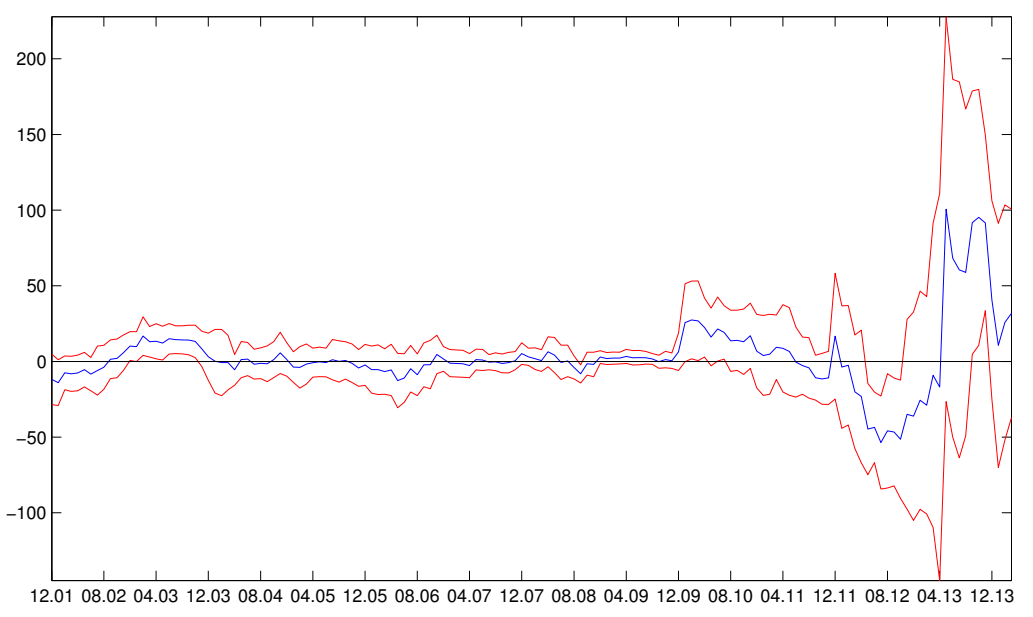

Figure 4: Rolling window OLS regression. Point estimate plotted in blue, 90 percent confidence band plotted in red.

we find a strong positive relation, increasing labor market efficiency, which helped to drive down the unemployment rate.

Overall we find a negative relation between search and financial frictions in the early 2000' recession and during parts of the Great Recession. Both of those two recessions were characterized by jobless recoveries. The time-instability adds another dimension to the problem and offers an alternative explanation for the emergence of jobless recoveries.

\subsection{A Vector Error Correction Model}

The model we consider is a five-dimensional system

$$
y_{t}=\left(m_{t}, F F_{t}, Y_{t}, U_{t}, V_{t}\right)^{\prime},
$$

with cointegrating rank $2 .{ }^{9}$ Then, the $\operatorname{VECM}(p)$ model is given by

$$
\Delta y_{t}=\mu+\Pi y_{t-1}+\sum_{i=1}^{p-1} \Gamma_{i} \Delta y_{t-i}+u_{t},
$$

where $\Pi=\alpha \beta^{\prime}$ with $\alpha$ and $\beta$ being $(K \times r)$ matrices, where $K$ is the dimension of the system and $r$ is the rank of $\Pi$. Further, $\Gamma_{i}$ are parameter matrices of size $(K \times K)$ and $\mu$ is an unrestricted constant. Finally, $u_{t} \sim\left(0, \Sigma_{u}\right)$ is white noise. A lag length test indicates that a lag of 12 months is optimal. Estimating this model with an unrestricted trend and constant using the five time series discussed earlier generates our main results discussed in the next sections. ${ }^{10}$

\footnotetext{
${ }^{9}$ As shown by a Johansen cointegration test with unrestricted trend and constant.

${ }^{10}$ We have performed several robustness checks including a restricted trend, no trend, the ordering in the VECM, and including other variables.
} 


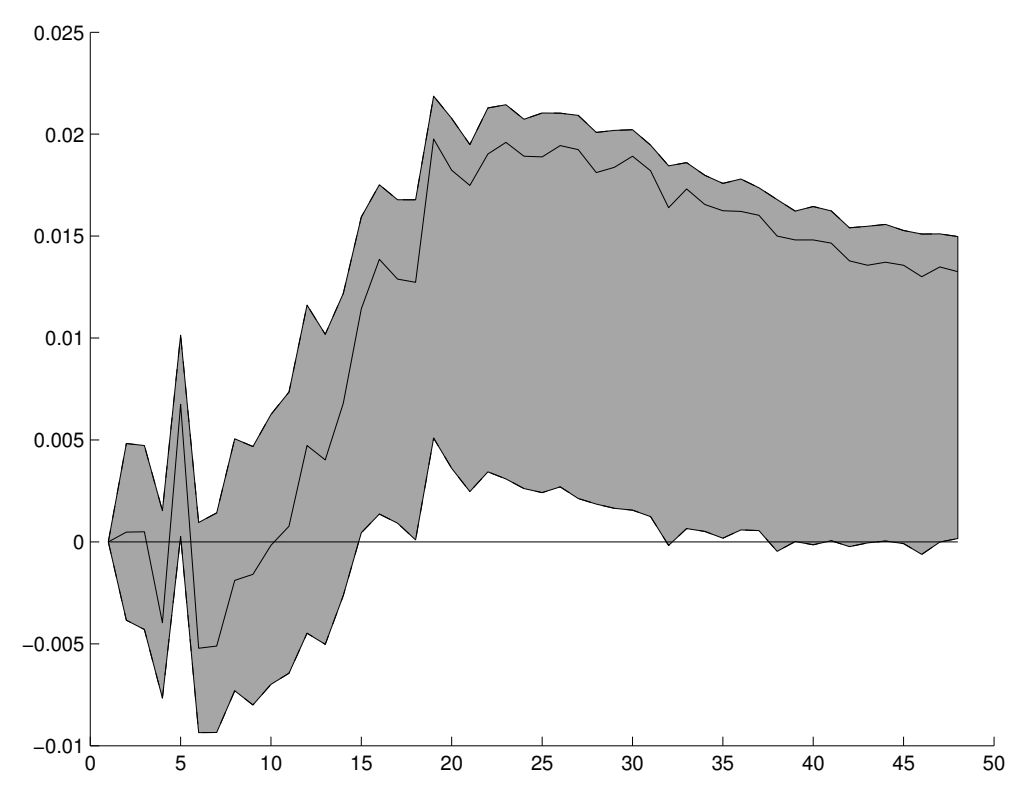

Figure 5: Response of match efficiency to a shock in financial frictions. Grey area is the $90 \%$ bootstrapped confidence band.

\subsubsection{Impulse Responses}

In this section we discuss the impulse responses of a shock in match efficiency and financial frictions. Figure 5 presents the response of the match efficiency to an one-standard error shock in financial frictions. We observe that the shock to financial frictions has no on-impact or short-run effects on the match efficiency. However, after roughly 15 months we find a significant positive effect. This effect varies between 0.005 and 0.02 , which is, given a mean of 1.15 with a standard deviation of 0.12 of the match efficiency time series, a fairly strong effect. This supports our conclusion that an increase in financial frictions will lead to a more efficient labor market. Further, the positive upshift holds for at least 15 months. We can conclude that the financial friction shock has significant, positive effects over the medium-run on the labor market. Figure 6 presents the response of the financial frictions to an one-standard error shock in match efficiency. We observe no significant effect of the change in the efficiency of the labor market towards the frictions in the financial market.

\subsubsection{Variance Decomposition}

Given that there is no significant effect of labor market frictions towards the financial market, we will continue and try to understand the driving forces of fluctuations in match efficiency. Figure 7 plots the contribution of each shock to the total variance in match efficiency over 48 months. On-impact, only the match efficiency shock drives the response in match efficiency. Then, over the short-run (less than a year) the shock to unemployment and vacancies are the main driving forces (both about 25 percent) of the fluctuations in match efficiency. After a year, the financial friction 


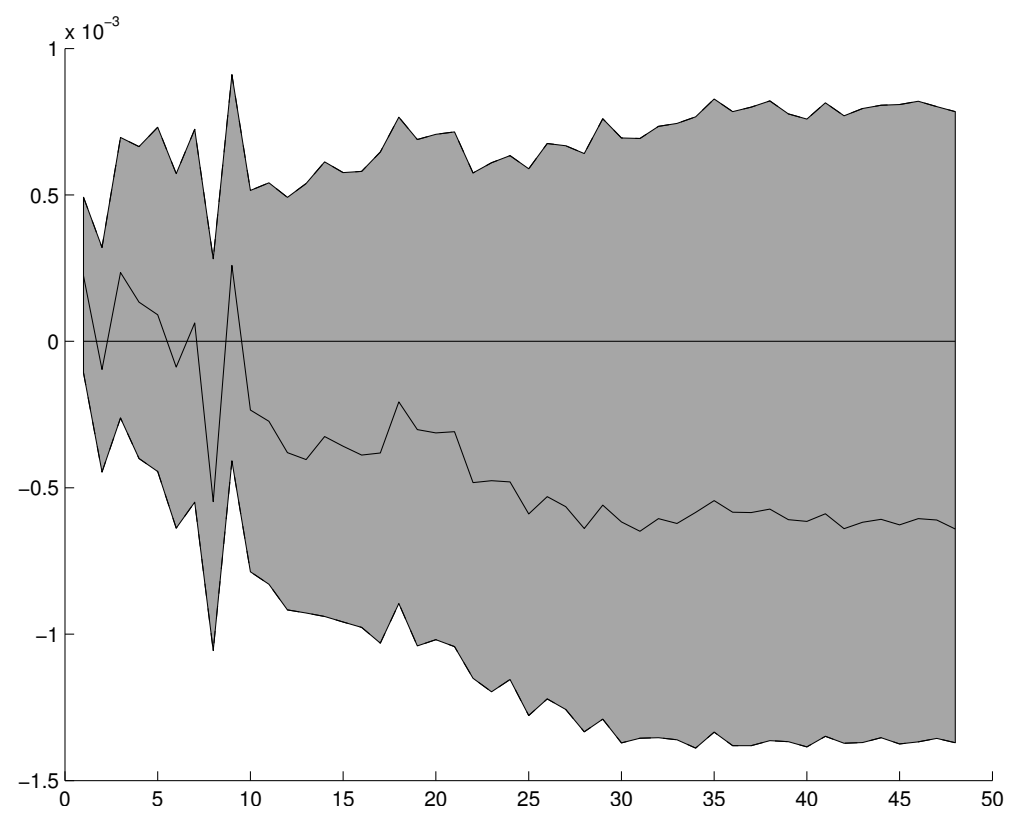

Figure 6: Response of financial frictions to a shock in match efficiency. Grey area is the $90 \%$ bootstrapped confidence band.

shock becomes more and more important and its importance increases from about five percent to more than 50 percent after 30 months. Over this medium-run the vacancies, unemployment, match efficiency, and GDP shocks contribute in descending order to the total fluctuation in match efficiency. Finally, over the long-run the financial friction shock explains about 60 percent of the total variance in match efficiency. The second main driver are innovations to vacancies, followed by unemployment shocks. Match efficiency and GDP shocks jointly explain about 10 percent of the variation in match efficiency over the long-run.

\section{A Dynamic Macro Model}

This section develops a dynamic, micro-founded macro model of the U. S. economy in discrete time with a link between labor market and financial frictions. We build a medium-scale DSGE model with search and matching frictions and the financial accelerator of Bernanke et al. (1999). A period is assumed to be a quarter. The model is close to the one used by Christiano et al. (2011), Mumtaz and Zanetti (2013), or Zanetti (2015).

\subsection{Household}

Our economy is populated by a continuum of infinitively-lived identical households, consisting of family members of measure one. Households equally share income and risk. Preferences are given 


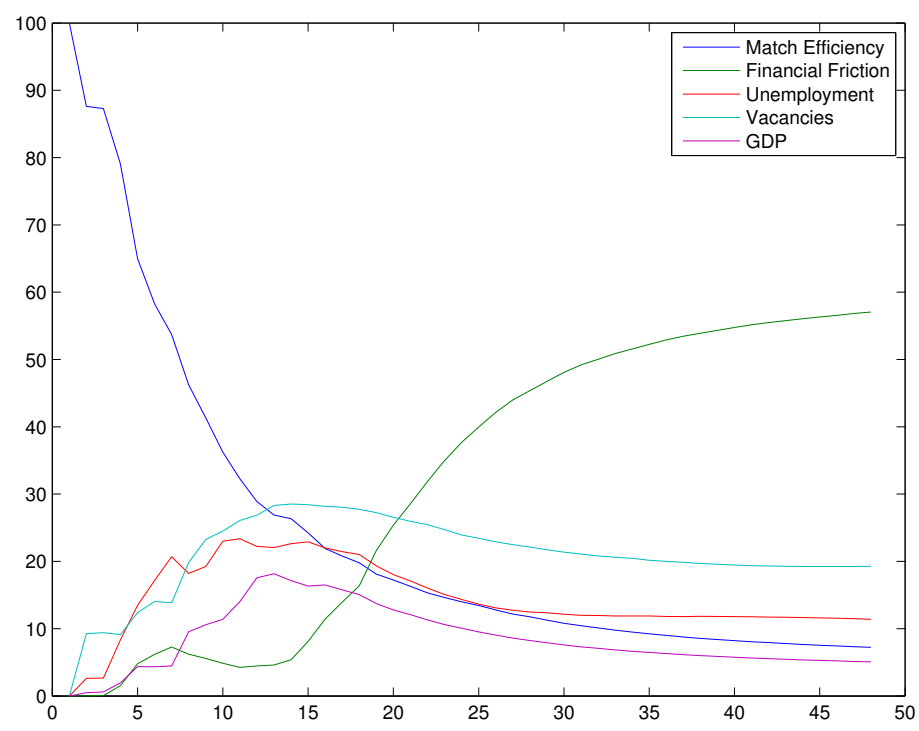

Figure 7: Variance decomposition for match efficiency over 48 months.

by the expected utility function

$$
\mathbb{E}_{0} \sum_{t=0}^{\infty} \beta^{t}\left[\ln \left(C_{t}\right)-\frac{N_{t}^{1+\vartheta}}{1+\vartheta}\right],
$$

where $\beta \in(0,1)$ is the discount factor and $\mathbb{E}$ is the mathematical expectation operator. Consumption is denoted by $C_{t}$ and labor units provided by the household is denoted by $N_{t}$.

Our economy begins with all households having identical financial wealth and consumption histories. Hence, this homogeneity continues and we are able to consider the optimal decisions of a representative household. The representative household maximizes utility subject to budget constraint

$$
R_{t-1} B_{t-1}+W_{t} N_{t}+\Pi_{t}+T_{t}+b U_{t}=P_{t} C_{t}+B_{t},
$$

where the household owns bonds, $B_{t}$, paying a gross nominal interest rate $R_{t}$. The household generates income from working, $W_{t} N_{t}$, from receiving transfers, $T_{t}$, and from profits, $\Pi_{t}$. Unemployed family members, $U_{t}=1-N_{t}$, receive unemployment benefits, $b$. The household than chooses consumption and bonds according to the following optimality conditions

$$
\begin{aligned}
\lambda_{t} & =\frac{1}{C_{t}}, \\
\lambda_{t} & =\mathbb{E}_{t}\left[\beta R_{t} \frac{\lambda_{t+1}}{\pi_{t+1}}\right],
\end{aligned}
$$

where $\lambda_{t}$ is the Lagrange multiplier on the budget constraint and $\pi_{t}=P_{t} / P_{t-1}$ is the inflation rate.

\subsection{Labor Market}

In contrast to the good market, the labor market is imperfect. We assume search and matching frictions on the labor market such that trade is uncoordinated, costly, and time-consuming. 
Each firm has one job that is either filled or vacant. They create jobs at the rate $M\left(U_{t}, V_{t}\right)$ at vacancy posting costs $c>0$. Here, $M$ is the matching function

$$
M\left(U_{t}, V_{t}\right)=m_{t} U_{t}^{\varphi} V_{t}^{1-\varphi}
$$

where $\varphi>0$ is the elasticity of the matching function w.r.t. unemployment, $V_{t}$ is the vacancy rate. Further, $m_{t}>0$ is the match efficiency. We assume the following specification

$$
m_{t}=\xi_{t}-\tau F F_{t-1}
$$

Financial frictions are defined as in eq. (5) and $\tau \geq 0$ governs the strength of the link between the two frictions. Further, there exists a match efficiency shock

$$
\begin{aligned}
\ln \xi_{t} & =\rho_{\xi} \ln \xi_{t-1}+e_{\xi, t}, \\
e_{\xi, t} & \sim \mathcal{N}\left(0, \sigma_{\xi}\right) .
\end{aligned}
$$

If the job is filled, it is subject to the probability of being exogenously destructed $\rho>0$. Then, labor market tightness is given by $\theta_{t}=V_{t} / U_{t}$ and the vacancy filling probability is $q\left(\theta_{t}\right)=M\left(U_{t}, V_{t}\right) / V_{t}$.

Combining entry and exit gives the law of employment

$$
N_{t}=(1-\rho)\left(N_{t-1}+M_{t-1}\right) .
$$

Wages are set via Nash bargaining between firm and worker. The value of being employed is given by

$$
\mathcal{W}_{t}^{N}=W_{t}-\frac{N_{t}^{\vartheta}}{\lambda_{t}}+\beta \mathbb{E}_{t}\left\{\frac{\lambda_{t+1}}{\lambda_{t}}\left[\left(1-\rho\left(1-q\left(\theta_{t+1}\right)\right)\right) \mathcal{W}_{t+1}^{N}+\rho\left(1-q\left(\theta_{t+1}\right)\right) \mathcal{W}_{t+1}^{U}\right]\right\} .
$$

Workers earn a wage while suffering the disutility from working. Further, if the job is not destroyed they receive the value of being employed in the next period. If the job is destroyed, they receive the value of being unemployed. The value of being unemployed is

$$
\mathcal{W}_{t}^{U}=b+\beta \mathbb{E}_{t}\left\{\frac{\lambda_{t+1}}{\lambda_{t}}\left[q\left(\theta_{t+1}\right) \mathcal{W}_{t+1}^{N}+\left(1-q\left(\theta_{t+1}\right)\right) \mathcal{W}_{t+1}^{U}\right]\right\} .
$$

Unemployed workers receive the value of being unemployed and the discounted, expected value of being employed with probability $q\left(\theta_{t+1}\right)$ or the value of staying unemployed.

The optimal wage follows the Nash solution

$$
\mathcal{W}_{t}^{N}-\mathcal{W}_{t}^{U}=\frac{\eta}{1-\eta} c
$$

where $\eta \in(0,1)$ is the worker's bargaining power. Using the value functions gives the optimal (real) wage

$$
W_{t}=\frac{N_{t}^{\vartheta}}{\lambda_{t}}+b+c \frac{\eta}{1-\eta}\left\{1-\beta(1-\rho) \mathbb{E}_{t}\left[\frac{\lambda_{t+1}}{\lambda_{t}}\left(1-q\left(\theta_{t+1}\right)\right)\right]\right\} .
$$

The wage depends on three factors. The disutility from working, the unemployment benefits, and the discounted, expected value of future hiring costs saved if the match continues. 


\subsection{Entrepreneurs}

Entrepreneurs use capital, $K_{t}$, and labor services, $N_{t}$, to produce wholesale goods. The production technology is Cobb-Douglas

$$
Y_{t}=Z_{t} K_{t}^{\alpha} N_{t}^{1-\alpha}
$$

where $\alpha \in(0,1)$ and $Z_{t}$ is a Hicks-neutral technology shock. It follows an autoregressive process

$$
\begin{aligned}
\ln Z_{t} & =\rho_{Z} \ln Z_{t-1}+e_{Z, t}, \\
e_{Z, t} & \sim \mathcal{N}\left(0, \sigma_{Z}\right),
\end{aligned}
$$

where $\rho_{Z} \in(0,1)$ is the autocorrelation parameter and its innovations are i.i.d. over time and normally distributed.

The capital accumulation technology is given by

$$
K_{t+1}=(1-\delta) K_{t}+I_{t}
$$

where $I_{t}$ is investment.

Entrepreneurs maximize profits and solve the following problem

$$
\mathbb{E}_{0} \sum_{t=0}^{\infty} \beta^{t} \lambda_{t}\left[Y_{t}-N_{t} W_{t}-c V_{t}-Q_{t} I_{t}\right] .
$$

subject to the production technology, the capital accumulation technology, and the law of employment. The first-order conditions are given by

$$
\begin{aligned}
W_{t} & =(1-\alpha) \frac{\varrho_{t}}{\lambda_{t}} \frac{Y_{t}}{N_{t}}-c \mathbb{E}_{t}\left[1-\beta(1-\rho) \frac{\lambda_{t+1}}{\lambda_{t}} \frac{1}{\pi_{t+1}}\right], \\
\lambda_{t} Q_{t} & =\beta \mathbb{E}_{t}\left[\alpha \varrho_{t+1} \frac{Y_{t+1}}{K_{t+1}}+\lambda_{t+1} Q_{t+1}(1-\delta)\right],
\end{aligned}
$$

where $\varrho_{t}$ are real marginal costs (the Lagrange multiplier on the production technology). The first equation pins down labor demand, while the second equation is an Euler equation for capital.

Entrepreneurs acquire physical capital being used to produce output. Acquisitions are financed by entrepreneurs net worth, $\nu_{t}$, and borrowing, $Q_{t} K_{t+1}-\nu_{t}$, from a financial intermediary. The financial intermediary obtains its funds from households savings at the riskless gross rate of return, $R_{t}$. The financial structure features an agency problem, namely the costly state verification approach. ${ }^{11}$ Due to the implied imperfectness of information, the Modigliani-Miller theorem does not longer hold and external financing becomes more expensive than internal financing.

The gross return of holding a unit of capital from period $t$ to $t+1, R_{t+1}^{K}$, is

$$
\mathbb{E}_{t}\left[R_{t+1}^{K}\right]=\mathbb{E}_{t}\left[\frac{\alpha \frac{Y_{t+1}}{K_{t+1}} \varrho_{t+1}+(1-\delta) Q_{t+1}}{Q_{t}}\right],
$$

\footnotetext{
${ }^{11}$ This agency problem makes external finance more expensive than internal funds due to auditing costs.
} 
which is the entrepreneur's demand for capital.

Then, the supply curve for investment is given by

$$
\mathbb{E}_{t}\left[R_{t+1}^{K}\right]=\mathbb{E}_{t}\left[s\left(\frac{\nu_{t+1}}{Q_{t} K_{t+1}}\right) R_{t+1}\right],
$$

The concave function $s(\cdot)$ is the gross external finance premium, i.e. the ratio of external and internal finance, and depends on the borrower's leverage ratio. ${ }^{12}$

Further, aggregate entrepreneurial net worth is given by

$$
\nu_{t+1}=\gamma \Delta_{t}+(1-\gamma) g_{t}
$$

The probability that an entrepreneur survives until the next period is denoted by $\gamma>0$. This assumption results implies that entrepreneurs will never acquire enough net worth to fully finance the new capital acquisitions. Further, $\Delta_{t}$ is period's $t-1$ net worth

$$
\Delta_{t}=R_{t}^{K} K_{t} Q_{t-1}-\mathbb{E}_{t-1}\left\{R_{t}^{K}\left[K_{t} Q_{t-1}-\nu_{t}\right]\right\}
$$

\subsection{Capital Producers}

Capital producers in our economy produce capital goods for the entrepreneurs buying final goods from retailers. They solve the following optimization problem

$$
\max _{I_{t}}\left\{Q_{t} I_{t}-I_{t}-\frac{\omega}{2}\left[\frac{I_{t}}{K_{t}}-\delta\right]^{2} K_{t}\right\},
$$

where $\omega>0$ and the latter term represents quadratic adjustment costs. The solution is given by

$$
Q_{t}=1+\omega\left[\frac{I_{t}}{K_{t}}-\delta\right]
$$

This is the well-known equation for Tobin's Q. Movements in asset prices affect Tobin's Q and then affect entrepreneurial net worth and therefore firm's optimal decisions.

\subsection{Retailers}

Our model features a continuum of monopolistically competitive retailers named $i \in[0,1]$. They use a Dixit-Stiglitz technology to produce total final output, $Y_{t}$

$$
Y_{t}=\left[\int_{0}^{1} Y_{t}(i)^{\frac{\phi-1}{\phi}} \mathbf{d} i\right]^{\frac{\phi}{\phi-1}},
$$

where $\phi>1$ is the demand elasticity and $Y_{t}(i)$ is the output sold by firm $i$. Then, the demand faced by firm $i$ is

$$
Y_{t}(i)=\left[\frac{P_{t}(i)}{P_{t}}\right]^{-\phi} Y_{t}
$$

\footnotetext{
${ }^{12}$ It satisfies $s(1)=1$ and $s^{\prime}(\cdot)>0$.
} 
where

$$
P_{t}=\left[\int_{0}^{1} P_{t}(i)^{1-\phi} \mathbf{d} i\right]^{\frac{1}{1-\phi}}
$$

is the price index.

Retailers set prices according to the Calvo (1983) pricing mechanism. Only a fraction $(1-\zeta)$ of firms is able to reset prices in a given period while the other firms are only able to update their prices for steady state inflation. The firm sets a new price $P_{t}(i)$ by solving the problem

$$
\mathbb{E}_{0} \sum_{j=0}^{\infty}(\beta \zeta)^{j} \frac{\lambda_{t+1}}{\lambda_{t}}\left\{\left[\frac{P_{t}(i)}{P_{t}}\right]^{-\phi} Y_{t+j}\left[\frac{P_{t}(i)}{P_{t+j}}-\varrho_{t+j}\right]\right\},
$$

again, $\varrho_{t}$ are real marginal costs. The optimality condition is given by

$$
P_{t}^{*}(i)=\frac{\phi \mathbb{E}_{t} \sum_{j=0}^{\infty}(\beta \zeta)^{j}\left[\lambda_{t+j} P_{t+j}^{\phi} Y_{t+j} \varrho_{t+j}\right]}{(\phi-1) \mathbb{E}_{t} \sum_{j=0}^{\infty}(\beta \zeta)^{j}\left[\lambda_{t+1} P_{t+j}^{\phi-1} Y_{t+j}\right]} .
$$

The aggregate price follows

$$
P_{t}=\left[\zeta P_{t-1}^{1-\phi}+(1-\zeta)\left(P_{t}^{*}\right)^{1-\phi}\right]^{\frac{1}{1-\phi}} .
$$

Finally, the New Keynesian Phillips curve is given by

$$
\hat{\pi}_{t}=\beta \mathbb{E}_{t}\left[\hat{\pi}_{t+1}\right]+\kappa \hat{\varrho}_{t}
$$

where $\kappa=(1-\beta \zeta)(1-\zeta) / \zeta$.

\subsection{Closing the Model and Calibration}

The monetary policy rule follows a standard Taylor-rule. This rule is given by

$$
R_{t}=\varkappa_{Y} Y_{t}+\varkappa_{\pi} \pi_{t}
$$

with the weights $\varkappa_{Y}>0$ on output and $\varkappa_{\pi}>0$ on inflation.

The market clearing condition is

$$
Y_{t}=C_{t}+I_{t}+c V_{t}+\frac{\omega}{2}\left[\frac{I_{t}}{K_{t}}-\delta\right]^{2} K_{t} .
$$

The model is then log-linearized around the non-stochastic steady state and calibrated on a quarterly basis for the United States according to empirical evidence and stylized facts.

The discount factor $\beta$ is 0.99 , which corresponds to an annual rate of $4 \%$. The labor share in the production function is set to a standard value of $2 / 3$. The quarterly exogenous capital depreciation rate is set to 0.025. Tobin's Q in steady state is set to 1 . In line with Bernanke et al. (1999), the investment adjustment costs are set to 0.25 , which is equal to the elasticity of the price of capital with regard to the investment capital ratio. The annualized business failure rate is set to $4 \%$. 
Steady state inflation is set to one percent. The elasticity of substitution is set to 11, such that steady state marginal costs are $10 / 11$. The Calvo probability is set to 0.60 . Monetary policy sets a weight of 1.5 on the inflation rate, satisfying the Taylor-principle and sets a weight of 0.125 on output.

Along the labor market dynamics of the model, we assume an unemployment rate of 12 percent. This rate accounts for the nonconformity of effective searchers and unemployed workers. The steady-state matching rate $q$ is calibrated to be 0.7 as in den Haan et al. (2000). Further, we assume symmetric bargaining between firm and worker and set $\eta=0.5$. Vacancy posting costs are calibrated to 0.05, which is close to the value used in Krause and Lubik (2007). Then, vacancies in steady state are $V=M / q$ and labor market tightness is $\theta=V / U$. The job separation rate is set to 0.06, close to the value used in Merz (1995) with 0.07. This implies a steady state match efficiency of $m=\rho N$.

Finally, the autocorrelation of both shocks is set to 0.9 .

\section{Discussion}

We begin with a discussion of the model dynamics generated by a positive match efficiency shock. Figure 8 presents the impulse responses for the standard model - without a link between the two frictions, i.e. $\tau=0$, - a weak, negative link $(\tau=10)$ and a strong, negative link $(\tau=50)$. The value of 50 for the strong link is taken from the rolling-window regression studied in section 3.2 , while the value of 10 is used for expository purposes.

As in Furlanetto and Groshenny (2012), the increase in match efficiency makes it easier for firms to fill vacancies because the job filling rate, $q_{t}$, increases. Unemployment decreases, as more unemployed workers find a job. Higher employment then increases output, consumption, and investment. At the same time, firms react to the increase in match efficiency with posting fewer vacancies, as they are - ceteris paribus - able to keep the same number of matches with lower vacancy postings. Financial frictions decrease because the difference between the return earned in business from operating physical capital and the safe rate decreases. Firm's net worth decreases initially but then overshoots and decreases towards the old steady state according to its process defined by eq. (31) and (32). Due to lower inflation and higher output the central bank lowers the interest rate in order to drive inflation back to the steady state. The effect of the link between search and financial frictions is very limited for the match efficiency shock. This is due to the fact that the shock itself has only a very limited effect on real factors and, most importantly, financial factors. Therefore dynamics in match efficiency are mainly governed by the shock process.

After discussing the match efficiency shock we turn to the dynamics generated by a positive, stationary technology shock and focus on how the link between search and financial frictions helps understanding jobless recoveries. Figure 9 presents the impulse responses for the standard model without a link between the two frictions, i.e. $\tau=0$, - a weak, negative link $(\tau=10)$ and a strong, negative link $(\tau=50)$. 

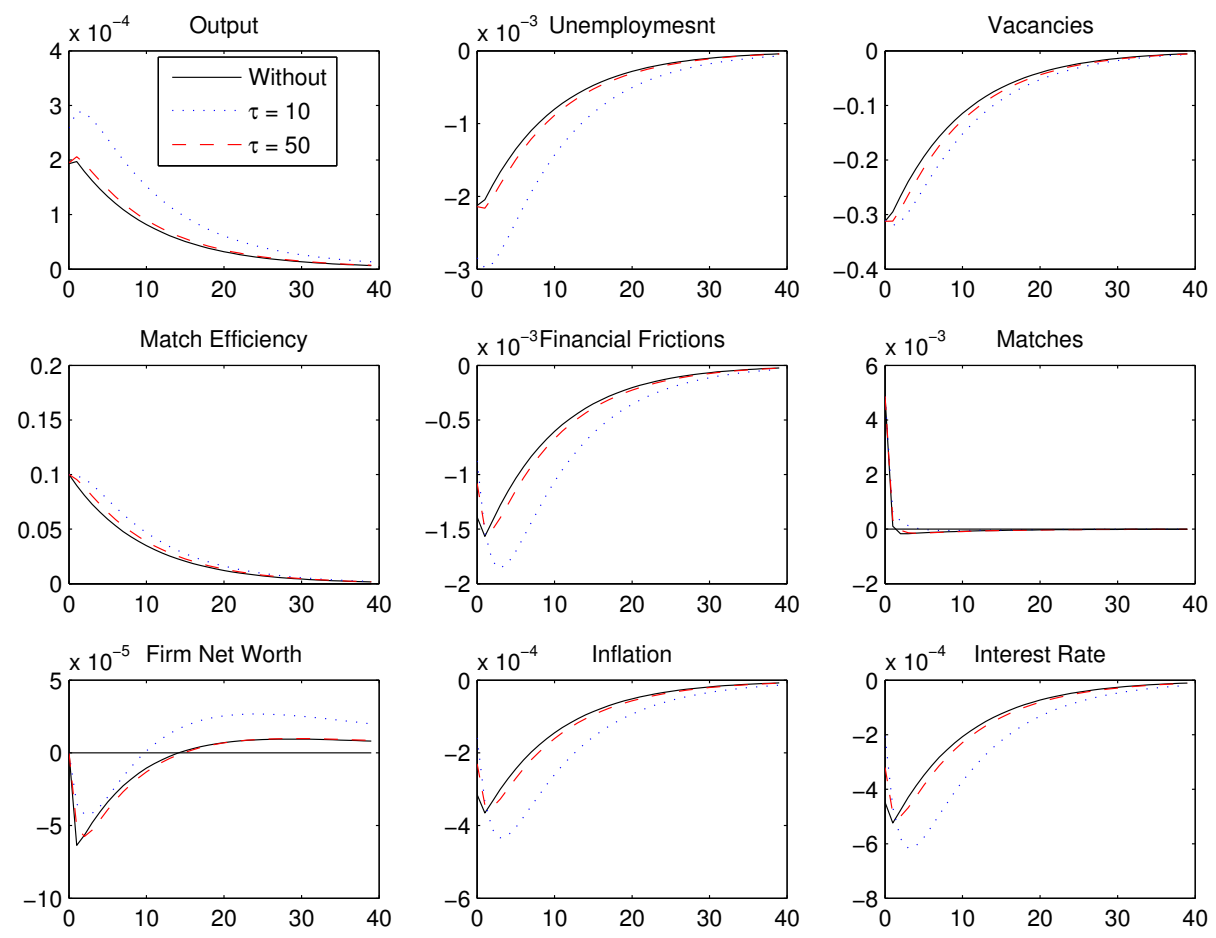

Figure 8: Impulse response functions for a match efficiency shock for the standard model (without) and a strong link $(\tau=5)$ between labor market and financial frictions. 
An increase in productivity shifts the production frontier outside allowing firms to produce more output. Incentives for the firms to raise the employment level are created by higher output and consumption. Firms increase vacancy posting and matches increase. The job-filling rate, $q_{t}$, drops due to the stronger increase in vacancies than in matches and labor market tightness increases. ${ }^{13}$ As a consequence, employment increases, unemployment decreases and we find a strong negative correlation between unemployment and vacancies, i.e. a Beveridge curve. According to the Nash bargaining solution, firm and worker share the increased surpluses and wages increase in response to the shock.

At the same time, higher productivity lowers marginal costs and, therefore, the inflation rate decreases. However, refinancing costs (asset prices) for firms increase and, jointly with the rise in wages, this increases marginal costs on impact. Higher output and lower inflation imply that, via the Taylor-rule, the central bank lowers the interest rate. Lower gross returns and the lower nominal interest rate reduce the risk premium. Financial frictions in our economy are reduced because of the lower safe rate and because the increase in Tobin's Q reduces the value of the extra units of output produced (cf. eq. (5)). Firm's net worth decreases on impact but quickly overshoots due to the additional capital holdings and higher capital prices (who caused the initial drop). The less frictional financial markets with higher net worth makes it easier for firms to borrow and investment increases.

What happens if we consider the model specification with the link between search and financial frictions? We have already discussed that financial frictions decrease and, with the negative link in place, now there is a channel from financial to labor market frictions that is absent in the standard model without the link. The drop in financial frictions now generates an increase in match efficiency. From figure 9 we can infer that the increase in match efficiency increases in the strength of the link between the two frictions. We have already learned about the dynamics triggered by an increase in match efficiency: vacancies decrease because the more efficient labor market allows the firms to increase matches even with less vacancies posted. In sum, there is lower unemployment while output, consumption, and investment increase. Given the positive effects from the technology shock, the additional increase of match efficiency leads to a much stronger response along the labor market. We observe hump-shaped adjustment paths for almost all variables (except matches and Tobin's Q) implying that the channel creates much more internal propagation of the technology shock. With higher output for a longer period of time, firms adjust differently along the capital side. Over time, they invest more and the increase in the capital stock is larger and, again, more persistent. This also implies that firm's net worth is larger compared to the model without the link. Moreover, marginal costs, due to the stronger response of wages and asset prices, stay above its steady state value for a longer period of time. Therefore, prices do not decrease as in the standard model and we observe upward pressure on the inflation rate. Hence, the central bank in our model, operating a Taylor-rule, increase the interest rate for several quarters until the inflation rate falls

\footnotetext{
${ }^{13}$ Intuitively, if a firm posts a vacancy, it decreases the probability of other firms filling a vacancy (congestion externality).
} 
below its steady state value. The link between search and financial frictions therefore changes the path of monetary policy in response to the technology shock.

Finally, we want to discuss the implications of this channel for the jobless recovery. If we compare the dynamics of the model with and without the link, we find that (i) output is slightly more sluggish and (ii) unemployment is strongly affected, featuring a large hump-shaped adjustment process. The link between the two frictions generates a strong internal propagation mechanism. Simulations of a one-off shock shows that the autocorrelation of output is hardly affected ( 0.14 vs. 0.16 ) but the one of unemployment is increased significantly: from 0.24 in the model without a link to 0.96 in the model with the link.

As a consequence, in the model with a link, output returns to its steady state long before unemployment does. This is not the case in the standard model without the link. If we would simulate a negative shock, the model would generate a jobless recovery. Further, the model dynamics are in line with the stylized empirical facts of the Great Recession: a simultaneous increase in financial frictions and a decrease in match efficiency as well as the jobless recovery. Further, vacancies in the model drop (increase in case of a negative shock) by about 20 percent once we consider the strong link. This is in line with the data from the JOLTS database reporting an increase of job postings of 32 percent from 2011 to 2013; the time the negative link is in place.

\section{Conclusion}

The Great Recession, like other recent recession in Europe and the United States, is characterized by a jobless recovery. While output returned to pre-crisis levels unemployment is still above its pre-crisis level. In this paper, we develop a link between labor market and financial frictions that offer an explanation for this observation. This direct link between the two frictions is a novelty in the literature.

The paper has an empirical and a theoretical contribution. Empirically, we find that financial frictions are a significant factor for the dynamics of match efficiency. Then, we document time variability in this relation and show that there was a negative link between the two time series during large parts of the Great Recession. Lastly, we estimate a VECM model and show that a shock to financial frictions increases match efficiency.

The theoretical contribution is to build a DSGE model with search and matching frictions and financial frictions including our new channel. We simulate the model and show that the model with a strong, negative relation between the two frictions generates a jobless recovery. The new channel creates a strong internal propagation mechanism and the simulated model dynamics are in line with the stylized empirical facts of the Great Recession. The model generates a simultaneous increase in financial frictions and a decrease in match efficiency observed in the empirical part.

One limiting factor of our study is the absence of a theory why the two frictions are related. We leave this to future research and focus on establishing the link in the data and present a model with this link in order to discuss the qualitative effects. 

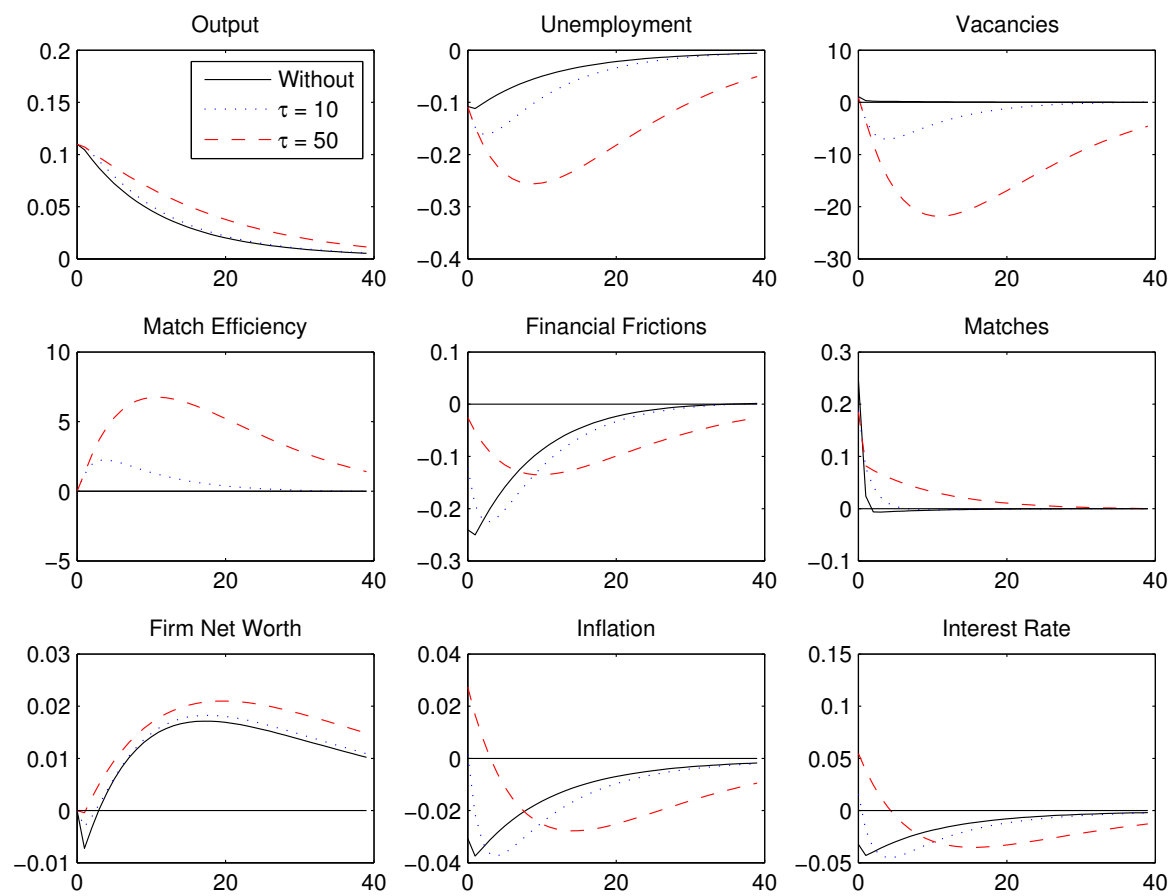

Figure 9: Impulse response functions for a technology shock for the standard model (without) and a strong link $(\tau=5)$ between labor market and financial frictions. 


\section{References}

[1] Barlevy, G., 2011. "Evaluating the Role of Labor Market Mismatch in Rising Unemployment." Economic Perspectives, Chicago FED, 3Q2011: 82-96.

[2] Bernal-Verdugo, L., D. Furceri, and D. Guillaume. 2012. "Crises, Labor Market Policy, and Unemployment." IMF Working Paper, no. 12/65.

[3] Bernanke, B. S., 2003. "The Jobless Recovery." Remarks by the Governor at the Global Economic and Investment Outlook Conference, Carnegie Mellon University.

[4] Bernanke, B., M. Gertler, and S. Gilchrist, 1999. "The Financial Accelerator in a Quantitative Business Cycle Framework." Handbook of Macroeconomics.

[5] Blanchard, O. and L. Summers, 1986. "Hysteresis and the European Unemployment Problem." NBER Macroeconomics Annual, 1: 15-90.

[6] Caggese, A. and A. Perez, 2015. The Interaction Between Household and Firm Dynamics and the Amplification of Financial Shocks." Mimeo.

[7] Calvo, G. A., F. Coricelli, and P. Ottonello, 2012. "The Labor Market Consequences of Financial Crises with or without Inflation: Jobless and Wageless Recoveries." NBER Working Paper, no. 18480.

[8] Calvo, G. A., 1983. "Staggered Prices in a Utility-Maximizing Framework." Journal of Monetary Economics, 12(3): 383-398.

[9] Chodorow-Reich, G., 2013. "The Employment Effects of Credit Market Disruptions: Firm-level Evidence from the 2008-09 Financial Crisis." Mimeo.

[10] Christiano, L. J., M. Trabandt, and K. Walentin, 2011. "Introducing Financial Frictions and Unemployment into a Small Open Economy Model." Journal of Economic Dynamics and Control, 35: 1999-2041.

[11] Chugh, S. K., 2009. "Costly External Finance and Labor Market Dynamics." Mimeo.

[12] Den Haan, W., G. Ramey, and J. Watson, 2000. "Job Destruction and Propagation of Shocks." American Economic Review, 90: 482-498.

[13] Furlanetto F. and N. Groshenny, 2012. "Matching Efficiency and Business Cycle Fluctuations." Norges Bank Working Paper 2012/07.

[14] Groshen, E. L. and S. Potter, 2003. "Has Structural Change contributed to a Jobless Recovery?" Current Issues in Economics and Finance, New York FED, 9(8): 1-7.

[15] Hall, R., 2013. "Financial Frictions." International Journal of Central Banking, 9(2): 155-163. 
[16] Krause, M. U. and T. A. Lubik, 2007. "The (Ir)relevance of Real Wage Rigidity in the New Keynesian Model with Search Frictions." Journal of Monetary Economics, 54(3): 706-727.

[17] Merz, M., 1995. "Search in the Labor Market and the Real Business Cycle." Journal of Monetary Economics, 36(2): 269-300.

[18] Mumtaz, H. and F. Zanetti, 2013. "The Effect of Labor and Financial Frictions on Aggregate Fluctuations." University of Oxford Economics Working Papers, no. 690.

[19] Mortensen, D. T. and C. A. Pissarides, 1994. "Job Creation and Job Destruction in the Theory of Unemployment." Review of Economic Studies, 61(3): 397-415.

[20] Petrongolo, B. and C. A. Pissarides, 2001. "Looking into the Black Box: A Survey of the Matching Function." Journal of Economic Literature, 39: 390-431.

[21] Petrosky-Nadeau, N., 2014. "Credit, Vacancies and Unemployment Fluctuations." Review of Economic Dynamics, 17(2): 191-205.

[22] Reinhart, C. and V. Reinhart, 2010. "After the Fall." NBER Working Paper, no. 16334.

[23] Smets, F. and R. Wouters, 2007. "Shocks and Frictions in US Business Cycles: A Bayesian DSGE Approach." American Economic Review, 97(3): 586-606.

[24] Veracierto, M., 2011. "Worker Flows and Matching Efficiency." Economic Perspectives, Chicago FED, 4Q2011: 147-169.

[25] Zanetti, F., 2015. "Financial Shocks and Labor Market Fluctuations." University of Oxford Economics Working Papers, no. 746. 